\title{
The Urgent Necessity for Learning and Using English as an International Dialect of Communication in the Arab School System and Universities: A Sociolinguistic Study
}

\author{
Faizah S. AlHammadi ${ }^{1}$ \\ ${ }^{1}$ Department of English, College of Arts, King Faisal University, AlAhsa, Kingdom of Saudi Arabia \\ Correspondence: Faizah S. AlHammadi, Department of English, College of Arts, King Faisal University, \\ P.O.Box 11758, AlAhsa 31982, Kingdom of Saudi Arabia. Tel: 966-505-916-986. E-mail: \\ falhammadi@kfu.edu.sa
}

Received: January 9, 2013 Accepted: January 30, 2013 Online Published: March 25, 2013

doi:10.5539/ijel.v3n2p46 URL: http://dx.doi.org/10.5539/ijel.v3n2p46

\begin{abstract}
Today, English has been carried around the world and has grown in use until it has become the second most widely spoken language of the world after Chinese and the first language in international use. Interestingly, while English is predominantly used by more people than any other language, its mother tongue speakers make up only "quarter" or a fifth of the total. This paper argues the need for an international variety of English to be taught in schools and universities in the Arab world. The international variety is defined as English that is understood by multilingual audience. It is a kind of English that is comprehensible outside the Arab world. The writer discusses the problem posed in adopting such a variety. The writer argues that what determines the use of English in Arab schools and universities should be the job, the hobby, or the field of study of students. English should be looked upon as a means of communicating and understanding each other in fields that require the uses of a language other than Arabic. The writer argues that the goal of teaching an international variety should not be acculturation so as to preserve the cultural identity of Arab speakers of English.
\end{abstract}

Keywords: international, dialect, variety, communication, native speaker, native-like pronunciation, ethno-centered, intelligibility

In Charles Dickens's times young students were provided with all the necessaries and instructed in all languages "living and dead" Nicholas Nickleby, C R.3). It is of great importance that the peoples of the Arab World have a reasonable knowledge of English since it has become an international language. The number of people who understand, let alone speak, Arabic is small and the Arab peoples are obliged to make use of English if they want to make contact with their friends abroad. Now, English is the most widely used language in the world: It is spoken as a first language by the majority populations of several sovereign states; is the third-most-common native language in the world, after Mandarin Chinese and Spanish; is widely learned as a second language; and is an official language of the European Union, many Commonwealth countries, and the United Nations, as well as many world organizations (Wikipedia, February 1, 2013).

Today, English has been carried around the world and has grown in use until it has become the second most widely spoken language of the world after Chinese and the first language in international use. Interestingly, while English is predominantly used by more people than any other language, its mother tongue speakers make up only a "quarter" or a fifth of the total.

The use of English falls into two major types: The "ethno-centered" and the "non-ethno-centered". Native speakers live in nations and communities in which English has an established role and thus have an ethno-centered use of the language. Non-native speakers have a "non-ethno-centered" use since the nationalities and linguistic histories of their countries are equally irrelevant. Their use of the language is determined by job, hobby, or field of study (Strevens, 1987, pp. 57-58). Indeed historical events have largely determined where English is used for ethno-centered purposes. But the borrowing and anglicizing characteristics of English have made the process easier and has contributed to a vast increase in the non-ethno-centered use.

Strevens argues that native speakers of English, especially of British English, should come to terms with the variations that occur among non-native speakers use of the language and should develop the feeling that English 
is no longer their own language but a language for world communication (Strevens, 1987, p. 56).

In the first part of this paper the writer argues the need for an international variety of English to be taught in schools and universities in the Arab world. The international variety is defined as English that is understood by multilingual audience. It is a kind of English that is comprehensible outside the Arab world. For instance, the English spoken by Saudis at the national level is useless at the international level. Likewise, the local Egyptian English spoken by the majority of Egyptians at the national level is both undesirable and useless at the international level because of problems of intelligibility.

In the second part of the paper the writer discusses the problem posed in adopting such a variety. The writer argues that what determines the use of English in Arab schools and universities should be the job, the hobby, or the field of study of students. English should be looked upon as a means of communication and understanding each other in fields that require the uses of a language other than Arabic. The writer argues that the goal of teaching an international variety should not be acculturation so as to preserve the cultural identity of Arab speakers of English.

Arab students, indeed, should not feel that they are compelled to acquire English and thus resign to a status of subordination as a result of the cultural and ideological dominance of the native speakers of British or American English. Educational authorities in most of the Arab countries tend to believe, wrongly, that the best and most efficient teacher of English is the native speaker of English. Arab students always complain about the difficulty of English and how hard it is. They hate the subject, and as a result, some fail in English. They feel that they have a psychological block towards English and the native speakers of English who teach them. Hence the writer argues the necessity of using English teachers whose native language is Arabic provided that they master the pronunciation of the English language.

However, Selinker (1972) points out that a perfect pronunciation is almost impossible to achieve among students. This is due to the fact that for most students, according to Selinker (1972) an inter-language pronunciation (foreign accent) tends to fossilize at some point and such a fossilized foreign accent is very resistant to change. We, as teachers should not accept such inter-language as models in our search for an international variety of English to be instituted and taught in our schools and universities.

It is legitimate to opt for an international variety of English in our schools, but some thought must be given to the characteristics of such a variety. We should have a native speaker of English as a model to follow and imitate. If we abandon the attempt to teach Arab students native speaker English and give them only a model with a heavy accent, such as Japanese English, the students cannot possibly achieve anything but a heavy accent. Of course, it is one thing to accept the probability that most students' pronunciation will fossilize at some point short of their native speaker model, but it is quite another thing to accept a model with a heavy accent such as Japanese (or for that matter) Russian English, (Schon \& Virginia, 1987, p. 25). There is great value in consistency. Imagine how confused the school or university students would be if they get American English the first year, British English the second year. Indeed, it is not recommended to shift the whole emphasis of the course too soon.

Tolerance towards the varieties of English in its spoken from and the idioms used in these varieties is acceptable on the part of teachers as specialists in teaching English because their ears should be tuned to different kinds of pronunciation whether it is British English, American English, Australian English, or even Indian English. However, they should insist (on the part of their students) on a particular correct pronunciation of a native speaker model.

English, as we know, have become the lingua franca of the world. Roughly 700 million people speak it - an increase of $40 \%$ in the last 20 years and a total that represents more than one seventh of the world's population. In the Arab countries, except for former French colonies, English is the sole non-native language taught in the public school system and universities.

Thus the question the teacher should always ask is "does my student sound like a native speaker of English?" Of course, a perfect pronunciation of English is almost impossible to achieve with all students. Indeed, the students who have the ability to achieve a near-native accent (especially those who have lived in the native speaker country) should not be denied the opportunity. In this context, the teacher should be able to set a model in his pronunciation so as to be emulated by his students.

However, striving for adequate intelligibility rather than native like perfection should be taken into consideration. We use English as an international variety to communicate. Thus students who cannot achieve near native pronunciation should not be denied the opportunity to communicate in the language. Again, perfect pronunciation of all sounds is not necessary to communicate. It is quite common to communicate well at the 
international level with someone who has a noticeable accent. Of the two, pronunciation and communication, communication is the more important. Usually our Arab students who do not acquire a native-like pronunciation, can acquire intelligibility and this is a reasonable goal.

Part of the difficulty of acquiring good pronunciation among Arab students is due to the failure of schools in the Arab world to emphasize the speaking and listening skills. In Arab schools, teachers of English are constrained by prescribed text books, prescribed materials, and the over present threat of examination based on reading and writing skills rather than on oral ability.

Strevens (1987) argues that good and correct pronunciation should be taken into consideration since students' accent counts very much if it interferes with the communication of the intended message. Some thought must be given, then, to the choice of a pronunciation model. We cannot allow our students to speak English with whatever accent they wish to have because this might threaten and lead to less than adequate standards for our English as an international variety. Whatever pronunciation model we opt for, we have to strive to make our students achieve native pronunciation. And unless they achieve that native pronunciation they will have an accent that is determined in large measure by the phonological patterns of Arabic, even at the level of "inter-language fossilization". A pronunciation model is necessary and the language laboratory helps the students a great deal in making the students rely on a model of pronunciation (British or American).

Of course, we have to set a number of criteria for the choice of a pronunciation model. But before we discuss the criteria, the characteristics of a standard for English as an international language must be given some thought.

For English as an international language, an international student does exist in vocabulary and grammar. No such standard exists for pronunciation. For instance, there is a new trend in Europe to use an international variety of English that is neither pure American nor British English, but a variety that is suitable for use for communication anywhere, is intelligible and international enough to be accepted by everyone. The so-called "Educated European English" is a new local form of English that has emerged and is used by business people, professional administrators from France, Germany, Holland, Italy, etc., to communicate and in which they recognize each other as European by performing in an English with common features, but each with his/her own accent (Schon \& Virginia, 1987, p. 24).

What is more important in this respect to be emphasized is that as long as teachers in the Arab world, and other parts of the world as well, continue to teach the lexico-grammar of educated English, the unity of the language will transcend its immense diversity. This one set of grammatical patterns and core vocabulary has two absolutely crucial characteristics. First, it is acceptable everywhere throughout the English using world, not just in one single locality. And second, it has in Strevens words no "twinned accent"; it is spoken with any and every accent in the world (Strevens, 1987, p. 62).

As far the set of criteria selected for the choice of a pronunciation model, Schon (1987) suggests three criteria: teachers may go along with the prevailing opinion in their area and teach the model that is most admired in that part of the world. Actually Smith and Rafigzad provide enough evidence to question the validity of native accent and native speaking patterns as English models to be emulated by non-natives who are speakers of other languages; and this, of course applies to speakers of Arabic (Smith and Rafigzad 1979).

Since the British were in the Arab world for a number of years, British English would be the type of English that is most suitable as a model. There is no inherent superiority of the British pronunciation model. Our choice stems from the fact that the British variety was the variety that was naturally imposed and taught in the Arab world schools for a long time. It was, out of necessity, then, that the Arabs used the British pronunciation model in their schools.

Like other parts of the world that were former colonies of the British Empire, the Arab countries maintained greater contact with Britain than with other English speaking countries. As a result, the tradition of teaching British English continued in Arab countries.

The recent criterion one might look at is the use the students will make of their English. An examination of any Arab country's x-year plan or a survey of university mission statements show a strong movement in the direction of development and modernization. The gates to development and modernization which took place in science and technology, are seen as English-dependent. As a consequence of their dependency, the status of English vis-à-vis other languages has become a foregone conclusion: English is more useful (and in some ways more prestigious) than other languages including the native language (Abuhamdia, 1984, p. 211).

In Arab countries, the situation, however, is compounded by the sentimental attachment of Arabs to Arabic, resulting in the current call and campaign to have Arabic replace a foreign language in the teaching of content 
subjects such as medicine and engineering. (At Syrian universities, for instance medicine is currently taught in Arabic). Consequently, Arabs find themselves caught in a dilemma, as they are torn between loyalty to Arabic, out of Islamic, ideological, cultural and nationalistic values, on the one hand, and the linguistic concomitants of importing and adopting technology from English-based sources, on the other.

Understandably, then, to the Arabs, English does have an essential instrumental value at both the individual and national levels. This utilitarian value appears particularly clear at the higher educational level, for which it has been imperative (Abuhamdia, 1984, p. 214). Thus, the field of study and sometimes the job determine the use of English by Arabs. Its importance, then, as an instrument for survival becomes apparent.

Since Arabs are in need of technology, we assume it (as opposed to politics) provides the ground for cultural neutrality (taking into consideration the negative attitudes of Arabs to British English as the language of British colonizers) on which the acquisition and the use of English can be promoted rather easily (Strevens, 1987, p. 60).

"The fact is that English can be deculturized, can be learned and used for purely instrumental purposes and can be separated from the value system and the literary culture of any society of native speakers "(Strevens, 1987, p. $60)$.

Although English is still remembered as the language of the colonizer and negative attitudes are associated with it, it is taught in Arab schools because of its utilitarian value. Because English is not the language of just one country (England originally, but now U.S., Canada, Australia, New Zealand, the Caribbean) there is already some neutrality in International English which has evolved naturally. However, this neutrality may involve the use of lexical items and auxiliary verbs, but definitely not pronunciation and probably not grammar since all English varieties, except Pidgins and Creoles, share essentially the same grammar with only surface level differences.

If Arab students view English neutrally as a subject of utilitarian value at present, they may not view western culture positively because it is difficult to separate western culture from western governmental policies in the area which can account for suspicion and sometimes hostility on the part of EFL students (Zughoul, 1980, p. 203). Indeed, language is a very emotional matter and the attitudinal factor is of utmost importance since positive attitudes towards the target language and its speakers result in motivation for learning the language.

The third criterion one may follow to choose a pronunciation model is the attitude of the school or university administration. In the Arab countries, except for former French colonies, British English pronunciation model is almost the sole pronunciation model taught in schools. Nevertheless, some schools teach American English pronunciation model. In many Arab countries those who do not know English are trying to learn either the British variety or the American variety. American English is taught in institutions such as the American University in Cairo (A.U.C.) or the American University in Beirut (A.U.B.) or other American centers established to teach U.S. bound adult students. There are also some other American private colleges and high schools established to serve the needs of the American community in the Arab world and Arabs who are interested in giving their children American education.

If our students fail to achieve native pronunciation but they are understood when they communicate with others, we should not worry much about their inability to reach that goal. Even if our students come very close to using an international variety such as the one used in Europe that is neither pure American nor British English, we should accept it as a legitimate one.

What we need to adopt then is an international kind of English with an international standard in grammar and vocabulary, an English that is understood by multi-lingual audience and comprehensible outside the Arab world. For example, a German English, a Japanese English, or even a Russian English are not acceptable simply because those Englishes are not dialects spoken in normal everyday life, but incomplete attempts to learn American English or British English or some other variety. We are not in need of a locally intelligible English at the national level such as the English spoken by Iraqis, Egyptians or Palestinians. This kind of English is useless at the international level. We need to adopt and teach a kind of English (British or American) which is completely comprehensible outside the Arab world.

Kachru (1981) emphasizes that there is a crucial distinction between national and international Englishes. He speaks of the "Cline" of intelligibility. For instance, a minority of educated Indians (like Kachru himself) who have an occasion to communicate at the international level are at one end of the cline, with Butler English and Boxwallah English (Peddler English) at the other end. Let the Indian Peddler, Kachru argues, use his Boxwallah English in the Indian villages, but let us all try to approach some major national standard when we talk to foreigners. What Kachru aims at is a national standard of Indian English as a necessary tool to communicate with 
foreigners outside India. For instance, the subdivisions of English and the greater variety do not impede comprehension among Indians themselves, but a particular variety of Indian English spoken with an uneducated accent outside India might not be intelligible because it is spoken by an uneducated Indian.

The development towards a variety of English that is called "English as a communication dialect (Beneka, 1981, p. 65) does exist. In the Arab world we are constantly in need of English as a means of communication at the international level. Among users of English as a means of communication in international context, there is a widespread readiness to tolerate a non-authentic (neither British nor American) "international variety" which is closely seen not as an 'interlanguage', a way stage on the road to perfection, but as a tool for communication in its own right, a final state.

It is necessary for a speaker of English as an international dialect to acquire a fully native control of the phonological system. The standardness/standardization of an international variety should relate to grammar first, then to vocabulary, and finally pronunciation. This does not mean that English as a communication dialect/variety does not reflect the native language phonological systems of its speakers. What we are against here is basing standardness/standardization on pronunciation. Some non-native accents should be considered positively. Distinctive foreign accents are associated with some non-native groups.

What Arab speakers of English need is to view English too, in a positive manner. If they fail to acquire a fully native control of the phonological system of English, they should neither feel frustrated nor tolerate the linguistic disorientation which occurs in the early stages of learning a new language. An attitude of outgoingness towards English is required since success in learning a language depends very much on such an attitude.

Foreign language users interviewed within international companies said great demands were made on their ability and willingness to adopt British or American cultural norms when it came to questions of using (and even) understanding conversational routines and specimens of written style that contained cultural specific element.

The writer subscribes to the view that with English as an international language, the goal in teaching it to Arabs (and this applies, too, to groups of other nationalities wishing to learn English as an international language) should not be acculturation, but getting the message with the message including a sense of personal identity. It is, in other words, not only the referential function of language that is required, but also its expressive function as well. It would be interesting to see how foreign language users could be encouraged to "color" their English with renderings from their own language so as to assert their own cultural identity. It would be a very limited view to expect the foreigner to forget his identity the moment he speaks English.

To express oneself in a foreign language in an international setting is an extremely difficult task. In order to function as signs, linguistic and paralinguistic/non-verbal features have to be used intentionally, consistently and arbitrarily. In a foreign language, there is always an element of doubt about this, the question that is frequently asked by foreign language users is: does the speaker mean what he says, and on his part as a speaker, does this particular linguistic form precisely reflect his intention? Is the use of one variant instead of another really a matter of choice, deliberate and therefore significant? Is the speaker silent because he lacks the words or is his silence intentional?

The linguistic competence of the foreign language user (especially in the area of grammar and vocabulary among Arab learners and users) is limited. Using English as an international language invites the foreign language learner and user to select (if he can select at all) from a small range of linguistic features. Use of features is neither deliberate nor consistent. There is uncertainty, too, if not conflict, as to the social norms governing behavior. He has to select from the totality of grammatical expressions available to him, those which appropriately reflect the social norms governing behavior in specific encounters (Gumperz, 1972, p. 205).

The foreign language user is at a loss as to which norms he should follow: the norms of the non-native speakers (i.e. Italian, Japanese, French, Arab) or the norms of the native speakers of English: Does he have to adopt totally the norms of the culture whose language he speaks as a foreign language?

Linguistic features, innocent in themselves, become socially significant only if they hold clearly defined positions within a field of related features. To give an example of British English: the phonological feature of dropping the ' $h$ ' co-occurs regularly with such features as informal colloquial style. Strictly speaking, there are no variants (in the socio-linguistic sense) at all in non-native speech (if we disregard bilingualism). Rather there are isolated linguistic features whose social significance is doubtful at best. For instance, the Arab user and learner of English does not have the linguistic competence to react to new social settings within which he can adjust and differentiate, for example, between degree of intimacy (e.g. friends - acquaintances - strangers) that presuppose different styles. 
In English as a foreign language, slang is usually not recommended) but then very informal or slangy variants are very unlikely in non-native speech, just very formal variants are unlikely. All of these variants presuppose a degree of flexibility on the part of the learner and user which would be utopian to strive for among Arab users of English as an international language.

In English, too, there exist phrases meant mainly for regulating social relationships and the structuring of discourse. They "take the edge off" what is being said, soften the blow "of critical remarks or "lubricate the conversation. The listener has to have a system of 'translating' these highly conventionalized forms, e.g. into degrees of politeness. More than anything else in language such forms are embedded in the cultural tradition of a society. They are of high importance for communicative competence since society holds them in store for ritualized exchanges, the sociolinguistic do's and dont's.

English has, also, a high degree of explicit, elaborate downtoners. For example, phrases such as 'well', I'm afraid I have got a bit of a problem' are used as introduction to confessing that one can't keep a promise or commitment. In other languages different grammatical features to tone utterances down are used. It, thus, seems that it is not the communicative competence that is deficient in the speakers of English as an international language, but rather the linguistic means to express it.

Indeed, Arab users of English apply their cultural norms wrongly to the English setting and infer a degree of intimacy, for example, from the use of first names which frequently is not meant to be implied. For example, English generally uses first names among peers, which is not, however, distinction of familiarity. In Arabic, as in French, specific forms are used to express degree of familiarity linguistically. Arab users of English, and I believe other foreign language users too, regularly identify "phatic communion" as a major problem area. It is the social uses of the language that are difficult for these users. For instance, acknowledging a compliment, reciprocating casual remarks beyond comments on the weather are felt to be difficult, , just as are commenting on aesthetic or emotional qualities or trying to be witty, sarcastic or comforting. There are, for example, typical comments one has to make as a listener to a story, to show interest or surprise, to encourage the narrator to continue.

A listener who does not produce responses such as 'oh really'; 'oh no'; 'oh dear'; 'that can't be true' appears to be inattentive or, worse, hostile, again without being aware of it and without having a chance of remedying it. A great many of these responses, especially in connection with the authentic intonation, are so culture specific that they are not readily mastered.

Other problems that Arab users of English encounter in the conduct of conversation are 'turn taking', 'opening gambits' and 'closing gambits'. Unfortunately, very little is known about the rules governing such encounters. 'Closing gambits' or 'conversational terminators', are on the other hand of great importance for the presentation of itself and the awareness of the other in fact-to-face interactions.

Those gambits are a problem because they are indirect means of expression. For instance, the lubrication of conversation gambits are full of concealed cultural values which make them difficult to use, sometimes antagonistic to the foreign user's system of values, and difficult to memorize because of their complex structure. Politeness formulas, too, are a problem for young users of English because they tend to memorize a few widely-used phrases and trot them out on all the occasions on which corresponding formulas in their first language would be appropriate.

The problem is that a pair of similar politeness formulas in two languages rarely turn out to be completely equivalent in all respects, while the foreign language learner groping for words is only too happy to assume that they are. A thoughtful discussion of some contrast between the formulas used by two cultures show that the true significance of a formula is determined by a complex of cultural and social conventions. (Daives, 1987, p. 77)

The successful language learner must not only know which formulas can be used for the performance of particular illocutionary acts where such acts can be appropriately performed: the kinds of behavior felt to call for thanks, the circumstances of, meeting where a greeting is appropriate and so on.

\section{Conclusion}

We should make users and learners of English as an international variety in our Arab world aware of all the problems touched upon briefly in this paper.

Indeed the acceptance of English as an international dialect of communication poses a serious problem, i.e. the problem of uncontrolled grammatical and stylistic degeneration. The communication dialect of English will have to be re-authenticated by a steady inflow of authentic English. As we have mentioned before, our model is the educated native speaker of English and we have, thus, to resort to the lexico-grammar of Educated English. As 
for the native speaker accent, teachers should encourage learners and students to strive very hard to emulate it and if some cannot reach that goal, they should not worry at all.

Smith and Rafigzad (1979) question the validity of native accent and native speaking patterns as English models to be emulated by non-native who are speakers of other languages.

Acculturation is not a realistic aim with regard to the lingua franca use of English and is no longer required by the foreign user. To guarantee the assertion of the socio-cultural identity of the Arab learner and user of English, some existing materials have to be rigorously scanned as to the ethnocentricity in content and linguistic features. Some forms in those materials are apparently ethnocentric and thus will not be acceptable especially by older students and learners who view English as the language of the old colonizer of most of the Arab world.

With those students, the following questions should be asked: Does the material presented to such adults invite the learner's identification? Are the paralinguistic aspects of the materials culturally neutral or culture-specific? The solution to such a problem is to develop and empirically validate a set of forms that are not ethnocentric and that learners can manage and accept. There is, indeed, no reason why anyone, because he speaks English, should not follow his own cultural traditions.

Given the massive exposure of our Arab world to the institutions and patterns of the Anglo-American system, the status of equivalence (the target language should be equivalent to the target language speaking group), which is one of the vital parameters of a successful language learning situation, is, unfortunately superseded by one of cultural and ideological dominance.

What ought to be done, then, is the development (at least for older students and adults) of a set of intercultural gambits' that are not ethnocentric but are meta-communicative, gambits that must be structurally and psycho-socially within the learners' range and at the same time suited to fulfilling the regulatory functions in interactions. These gambits have to be empirically tested with Arab learners and users of English as to their structural manageability for a variety of communicative settings.

The argument is not for a new brand of English in international settings. If the speakers of Arabic are to be permitted their own brand of English, then the speakers of all other languages should be permitted their own brand and that means there should be no international standard English for communicative purpose. We should not isolate the Arabs from that portion of the world that uses English in international communication. As non-native speakers of English, emphasis in learning and using English for international communication should be laid on the non-ethnocentric' use of the language since such use is determined by the job, hobby, or field of study of students.

We are not arguing that Arabs should acculturate International English to their own language/culture, otherwise there could never be an international standard. Some materials that are taught in the Arab world are not related to the students local values, culture, customs and traditions. Alptekin (1984) subscribes to the view that native speakers of English in the third world who work as teachers attempt, in their teaching the language, to modify the students' cognitive and affective behavior so as to concentrate on Western values and ideas of the Western culture. Such attempts make students (in our case Arab students) hesitate to accept those values and ideas (of the Western culture) and even to resist them.

Wilkins, too, subscribes (see Wilkins 1975) to the view that the values and cultural traditions which accompany the process of cultural transfer from English speaking countries are often considered alien and thus, considered unacceptable to the indigenous culture of the students. That is why it has been increasingly recognized in contemporary reading texts that the cultural characteristic of the learner and user should be considered in the development of reading materials and instructional methods.

It has been proved, for instance, that the motivation of Hispanic students studying in the United States schools has increased substantially when the reading matter in English textbooks reflected their preferred cultural context.

As a matter of fact, the learner's ethnocentric tendencies and his attitudes towards the members of the other group are believed to determine how successful he will be, relatively, in learning the new language. As we mentioned before, his motivation to learn is thought to be determined by his attitude to the other group in particular and toward foreign people in general, and by his orientation toward the learning task itself. The orientation is said to be instrumental in form if the purposes of language study reflect the more utilitarian value of linguistic achievement, such as getting ahead in one's profession. In contrast, the orientation is integrative if the student wishes to learn more about the other cultural community because he is interested in an open-minded way, to the point of eventually being accepted as member of the other group (Gardner \& Lambert, 1959). Again 
the reading comprehension of the Hispanic students studying in the U.S. schools, thus, has improved with the use of translated readers from the Spanish language.

There is no harm, then, in presenting the culture of Arab students when learning English. Arab learners and users should also be given the chance to comment on the socio-cultural norms of their own culture and compare and contrast them with the socio-cultural norms of the native English speaking countries. In this way their own cultural identities could be asserted.

There is no harm, too, in encouraging Arab students who learn English as an international language to color their English with renderings from their own language. This is acceptable as long as they are aware of the fact that the form is not an authentic English form and should therefore be used only for a particular occasion, i.e. a communicative variety created for the time being only.

Hence, the result will be an occasional focus on 'poetic' function of language (in Roman Jakbson's) sense, language that draws attention to itself. This should help to show the problem of the 'flatness', the expressive poverty of the stylistically unmarked, neutralized foreign use of English. For instance, Arab users and learners of English could refer to idiomatic expressions of their own language and enrich the communicative dialect of English with exotic and poetic elements that could be introduced or commented on by "as we say in Arabic" or "in Arabic we have an expression", so that the Arab user and learner would add something from his own language to the variety of English as an international language.

The above are only some of the problems that need to be dealt with in discussing English as an international dialect of communication in the Arab school system and universities. More research needs to be done in how to deal with such problems.

\section{References}

Abuhamdia, Z. (1984). English departments at Arab universities: Toward a planning-based model. Language Problems and Language Planning, 8, 211-214. http://dx.doi.org/10.1075/lplp.8.1.02abu

Alptekin, C., \& Alptekin, M. (1984). The question of culture: EFL teaching in non-English-speaking countries. ELT Journal, 38(1), 14-20. http://dx.doi.org/10.1093/elt/38.1.14

Davies, E. (1987). A contrastive approach to the analysis of politeness formulas. Applied Linguistics, 8(1), 77. http://dx.doi.org/10.1093/applin/8.1.75

Dickens, C. (1839). Life and Adventures of Nicholas Nickleby.

English Language. (2013, February). In Wikipedia, the free encyclopedia. Retrieved February 1, 2013, from http://en.wikipedia.org/wiki/English_language

Freudenstein, R., Beneke, J., \& Pönisch, H. (1981). Cultural monsters: Mimicry and English as an international language. Language Incorporated: Teaching Foreign Languages in Industry (p. 65). London: Pergamon Institute of English.

Gardner, R. C., \& Lambert, W. E. (1959). Motivational variables in second-language acquisition. Canadian Journal of Psychology, 13, 266-272. http://dx.doi.org/10.1037/h0083787

Gumperz, J. (1972). Sociolinguistics and communication in small groups. In J. B. Pride, \& J. Holmes (Eds.), Sociolinguistics (pp. 203-224). Harmondsworth, UK: Penguin Books.

Kachru, B. (1981). The pragmatics of non-native varieties of English. In L. Smith (Ed.), English for Cross-Cultural Communication (pp. 15-39). London: Macmillan.

Schon, V., \& Virginia, C. (1987). The question of pronunciation. English Teaching Forum, XXV(4), 22-25.

Selinker, L. (1972). Interlanguage. In IRAL, 10(3), 409-427.

Smith, L., \& Rafigzad, K. (1979). English for cross-cultural communication: The question of intelligibility. TESOL Quarterly, 13(3), 371-380. http://dx.doi.org/10.2307/3585884

Strevens, P. (1987). English as an international language. Forum, XXV(4), 56-62.

Waugh, L. (1980). Roman Jakobson: Language and Poetry. Poetics Today, 2(1a), 57-82. http://dx.doi.org/10.2307/1772352

Waugh, L. (1980). The Poetic Function in the Theory of Roman Jakobson. Poetics Today, 2(1a). http://dx.doi.org/10.2307/1772352

Wilkins, D. (1975). Second-Language Learning and Teaching. London: Edward Amold.

Zughoul, R. (1980). Diglossia in Arabic: Investigating solutions. Anthropological Linguistics, 22(5), 203. 